\title{
Individual differences in magnitude estimation of loudness
}

\author{
A. W. LOGUE \\ Harvard University, Cambridge, Massachusetts 02158
}

\begin{abstract}
Twenty-two male and female subjects, aged 15 to 31 years, participated in two sessions, 11 weeks apart, of magnitude estimations of loudness. Stable individual differences in the exponent of the psychophysical power law, $\psi=k \phi^{n}$, were shown. The correlation between subjects' exponents of - the first and second sessions was +.59 . The generality of these findings and the origin of the individual differences were discussed.
\end{abstract}

Large individual differences in the exponent of Stevens' power law, $\psi=\mathbf{k} \boldsymbol{\phi}^{\mathbf{n}}$, have been observed by many authors (Bernyer, 1962; Ekman, Hosman, Lindman, Ljungberg, \& Akesson, 1968; Garner, 1954; McGill, 1974). These differences have generally been attributed to perceptual system noise or measurement error. Averaging across subjects is used to remove these effects (see, for example, S. S. Stevens, 1971). Such averaging does yield similar exponents for a particular modality. But the representativeness of a mean exponent would be questionable if individual differences in exponents were stable over time and across modalities.

The bulk of the evidence suggests that there are reliable individual differences in the size of the exponents of the psychophysical power law (Ekman et al., 1968; Jones \& Marcus, 1961; McGill, 1974; Pradhan \& Hoffman, 1963; J. C. Stevens \& Guirao, 1964). However, the most complete study (Teghtsoonian \& Teghtsoonian, 1971) concluded that psychophysical differences between individuals were ephemeral.

Teghtsoonian and Teghtsoonian had subjects give magnitude estimations of area twice with varying times between the two sessions. The only significant correlation, +.82 , was that for a 0 delay between the sessions. Intervals between 1 day and 8 weeks all resulted in nonsignificant correlations of about +.4 . An 11-week delay showed a correlation of 0 between exponents. From these data, the Teghtsoonians drew the conclusion that "the factors that produce [real individual differences in exponents] are stable for such short periods of time that they cannot be regarded as enduring individual characteristics"

This research was supported by a grant from the National Science Foundation. The assistance of $W$. Jesteadt with the experiment is gratefully acknowledged. Comments on a preliminary draft by $\mathbf{M}$. Teghtsoonian were greatly appreciated. The author would especially like to thank D. M. Green for his advice and support. The author is a National Science Foundation Graduate Fellow. Requests for reprints should be sent to A. W. Logue, 760 William James Hall, 33 Kirkland Street, Harvard University, Cambridge. Massachusetts 02138 . (p. 149). However, Engeland and Dawson (1974), failing to confirm these results for judgments of visual area, found a significant intersession correlation with a 1-week delay.

Subjects in the experiment to be reported here also made magnitude estimations twice, with 11 weeks, the Teghtsoonians' longest delay, between the two sessions. Judgments of loudness were used in order to see whether the Teghtsoonians' results would obtain in another continuum.

\section{METHOD}

The subjects were 18 males and 4 females between the ages of 15 and 31 years. Most of the subjects had not previously participated in magnitude estimation experiments. Each was paid $\$ 2$ for taking part in two 10-min sessions.

At each of the two sessions, subjects heard $261,000-\mathrm{Hz}$ tones of $.5 \mathrm{sec}$ duration presented by a PDP-15 computer. The tones were presented binaurally through Superex headphones. The subjects sat in a sound-attenuated (IAC, single-wall) chamber. The tones varied from 30 to $90 \mathrm{~dB}$ SPL in steps of $5 \mathrm{~dB}$, with each of the 13 stimuli being presented twice. No standard was designated and no modulus assigned. responses were made on a Video System Teletype, and could be either whole numbers or decimals. After a subject had typed in his response, he pushed the return key and then the next tone was presented. Thus, the presentation of stimuli was self-paced. Most subjects took about $5 \mathrm{~min}$ to complete judgment of the 26 tones.

Subjects were randomly assigned to one of two groups. The first group heard the same random sequence of tones at both sessions. The second group heard a different random sequence at each session. This was done to control for possible sequence effects (Cross, 1973). The two sessions were about 11 weeks apart $(M=$ 77.6 days, $S D=1.6$ days). A subject's second session was at the same time of day-morning, afternoon, or evening - as his first session. The subjects were read the experimental instructions at both sessions and were told to use any numbers they felt appropriate, though making the ratios of their numbers proportional to the ratios of the loudnesses.

\section{RESULTS AND DISCUSSION}

Exponents were calculated for each subject at both sessions by using a geometric mean of subjects' responses at each decibel level, and fitting a line to the averaged points by the method of least squares. A summary of the experiment's results is shown in 
Table 1

Summary of Exponents and Correlations

\begin{tabular}{|c|c|c|c|c|}
\hline \multirow[b]{2}{*}{ Session } & & \multicolumn{3}{|c|}{ Stimulus Order for Two Sessions } \\
\hline & & Same & Different & Total \\
\hline First & $\begin{array}{l}\text { Mean } \\
\text { SD }\end{array}$ & $\begin{array}{l}.26 \\
.091\end{array}$ & $\begin{array}{l}.25 \\
.040\end{array}$ & $\begin{array}{l}.25 \\
.070\end{array}$ \\
\hline Second & $\begin{array}{l}\text { Mean } \\
\text { SD }\end{array}$ & $\begin{array}{l}.28 \\
.076\end{array}$ & $\begin{array}{l}.25 \\
.089\end{array}$ & $\begin{array}{l}.27 \\
.084\end{array}$ \\
\hline \multirow[t]{2}{*}{ Total } & $\begin{array}{l}\text { Mean } \\
\text { SD }\end{array}$ & $\begin{array}{l}.27 \\
.084\end{array}$ & $\begin{array}{l}.25 \\
.069\end{array}$ & $\begin{array}{l}.26 \\
.077\end{array}$ \\
\hline & $\begin{array}{l}n \\
r_{x y}\end{array}$ & $\begin{array}{l}11 \\
.69^{* *}\end{array}$ & $\begin{array}{l}11 \\
.58^{*}\end{array}$ & $\begin{array}{l}22 \\
.59^{* *}\end{array}$ \\
\hline
\end{tabular}

Table 1. First- and second-session mean exponents were comparable, .25 and .27 , respectively. ${ }^{1}$ These values are below the generally established figure of .33 for the power law exponent for loudness (S. S. Stevens, 1975). However, Stevens found that the method of magnitude estimation can underestimate the exponent to an extent similar to this experiment.

Despite an 11-week interval, subjects did show consistency in loudness magnitude estimation. The correlation for all subjects between first- and second-session exponents is highly significant, and about one-third of the variance of the exponents is accounted for by the individual subject. There were no significant differences between the same and different groups, either in terms of the exponent means or of the correlation coefficients. Thus, the stability of the individual exponents over time could not be due to an artifact from a constant order of stimuli.

It remains to be determined whether stability of individual exponents differs among continua. The existing data would suggest this to be so. This report has extended the finding of Wanschura and Dawson (1974) of stability of the loudness exponent when very short intersession durations are used. The exponent for apparent duration was also shown to manifest temporal stability by Wanschura and Dawson. The apparent length exponent has not shown stability over time (Teghtsoonian \& Teghtsoonian, 1971). Conflicting results have been reported for stable individual differences using apparent area (Engeland \& Dawson, 1974; Teghtsoonian \& Teghtsoonian, 1971).

Once the individual exponents for a continuum have been shown to manifest temporal stability, the question remains, what is the origin of this stability? One answer is that the stability is due to a response bias resulting from some kind of a learning process (McGill, 1974; J. C. Stevens \& Guirao, 1964; J. C. Stevens \& Mack, 1959), Ekman et al. (1968) stated that an important source of response bias "may be S's interpretation and handling of the numbers used in scaling experiments" (p. 822). A second possibility is that the differences between subjects are due to their physiology. Bernyer (1962) thought it likely that his subjects judged weights according to the different amounts of muscular effort subjects had to expend to lift the weights. S. S. Stevens (1961) has said that the nature of the sensory transducers may contribute to individual differences, though he believed this would account for only a small part of the variance. However, there is no difference in behavior between an exponent determined by learned response patterns and one determined by a relatively permanent physiological structure. This problem remains to be solved.

In conclusion, lasting individual differences can be shown for the exponent of the psychophysical power law for magnitude estimation of loudness. This may be due to a subject's learned handling of numbers or to more permanent structural factors, and these should be investigated in more detail.

\section{REFERENCES}

Berwyer, G. Étude sur la validité d'une échelle de sensation d'effort musculaire. Année Psychologique, 1962, 62, 1-15.

Cross, D. V. Sequential dependencies and regression in psychophysical judgments. Perception \& Psychophysics, 1973, 14, 547-552.

Ekman, G., Hosman, B., Lindman, R., LuUngberg, L., \& Akesson, C. A. Interindividual differences in scaling performance. Perceptual and Motor Skills, 1968, 26, 815-823.

Engeland, W.. \& Dawson. W. E. Individual differences in power functions for a 1-week intersession interval. Penception \& Psychophysics, 1974, 15, 349-352.

GARner, W. R. Context effects and the validity of loudness scales. Joumal of Experimental Psychology, 1954, 48, 218-224.

Jones, F. N., \& Marcus, M. J. The subject effect in judgments of subjective magnitude. Journal of Experimental Psychology, $1961,61,40-44$.

McGill, W. J. The slope of the loudness function: A puzzle. In H. R. Moskowitz, B. Scharf, \& J. C. Stevens (Eds.), Sensation and measurement. Boston: Reidel, 1974.

Pradran, P. L., \& Hoffman, P. J. Effect of spacing and range of stimuli on magnitude estimation judgments. Joumal of Experimental Psychology, 1963, 66, 533-541.

Stevens, J. C., \& Guirao, M. Individual loudness functions. Journal of the Acoustical Society of America, 1964, 36. 2210-2213.

Stevens, J. C., \& MAck, J. D. Scales of apparent force. Journal of Experimental Psychology, 1959, 58, 405-413.

STEVENS, S. S. The psychophysics of sensory function. In W. A. Rosenblith (Ed.), Sensony communication. New York: M.I.T. Press and Wiley, 1961.

STEvens, S. S. Issues in psychophysical measurement. Psychological Review, 1971, 78, 426-450.

Stevens, S. S. Psychophysics. New York: Wiley, 1975.

Teghtsoonian, M., \& Teghtsoonian, R. How repeatable are Stevens's power law exponents for individual subjects? Perception \& Psychophysics, 1971, 10, 147-149.

Wanschura, R. G., \& Dawson, W. E. Regression effect and individual power functions over sessions. Journal of Experimental Psychology, 1974, 102, 806-812.

\section{NOTE}

1. Exponents were calculated using energy flow as $\Phi$. If sound pressure had been used, the values for all exponents would be doubled.

(Received for publication October 20, 1975 . revision received January 12,1976 .) 